\title{
Determination of Four Metal Elements in Chicken Feed by Microwave Digestion-HR-CS FAAS
}

\author{
Shang-long Chen ${ }^{a}$, Chao $\mathrm{Li}^{\mathrm{b}}$, Yong $\mathrm{Li}^{\mathrm{c}, *}$, Shi-yu Jiang ${ }^{\mathrm{d}}$, Yun-Xu Zhu ${ }^{\mathrm{e}}$ \\ Jiangsu Key Laboratory of Food Resource Development and Quality Safe, Xuzhou Institute of \\ Technology, Xuzhou China 221111 \\ aslchen1982@163.com, b305786072@qq.com, c1507674085@qq.com, d1303681935@qq.com, \\ e609116239@qq.com
}

Keywords: metal element; chicken feed; microwave digestion; HR-CS FAAS

Abstract. A new application of high resolution continuum source flame atomic absorption spectrometry has been developed for the determination of $\mathrm{Ca}, \mathrm{Fe}, \mathrm{Zn}$ and $\mathrm{Mn}$ in chicken feed. Under the selected determination conditions, the correlation coefficients better than 0.998, the relative standard deviations less than $2.6 \%$ and the recoveries between $96.3 \%$ and $103.1 \%$ were obtained for the four metal elements. The characteristic concentrations were $0.092 \mathrm{mg} / \mathrm{L}(\mathrm{Ca}), 0.17$ $\mathrm{mg} / \mathrm{L}(\mathrm{Fe}), 0.033 \mathrm{mg} / \mathrm{L}(\mathrm{Zn})$ and $0.15 \mathrm{mg} / \mathrm{L}(\mathrm{Mn})$, respectively. The results showed that the contents in chicken feed were $6.75 \pm 0.12 \mathrm{mg} / \mathrm{g}(\mathrm{Ca}), 1.30 \pm 0.03 \mathrm{mg} / \mathrm{g}(\mathrm{Fe}), 0.174 \pm 0.05 \mathrm{mg} / \mathrm{g}(\mathrm{Zn})$ and $0.313 \pm 0.04 \mathrm{mg} / \mathrm{g}(\mathrm{Mn})$, respectively. Therefore, the proposed method was accurate and stable with a high practical value. It provided scientific basis for determination of metalelements in food.

\section{Introduction}

Several sample preparation techniques are used for the determination of metal elements in food, such as inductively wet digestion, dry digestion, incomplete digestion and microwave digestion. Wet digestion and dry digestion are two traditional ways, but both of them have obvious disadvantages, for instance, some dense mass of strong acids are used in wet digestion, while dry digestion is a time-consuming process[1,2]. The objective of incomplete digestion is uniform and transparent digestive solutions, which do not need of complete destruction and colorless liquors. As a consequence of that, the sample-process time just need less than $20 \min [3]$. Nevertheless, incomplete digestion also requires a good deal of strong acids and the microemulsification stability after that is an important parameter for accurate analysis. Closed-vessel microwave-assisted digestion need only $5 \mathrm{~mL}$ of $\mathrm{HNO}_{3}$ and $4 \mathrm{~mL} \mathrm{H}_{2} \mathrm{O}_{2}$ in this study, and its main advantages are the high relative speed, good reproducibility, low blank, low possibility of contamination and the minimum loss of volatile elements [4].

The objective of this study was to develop a simple and robust method for the fast sequential multi-element determination of $\mathrm{Ca}[5], \mathrm{Fe}[6], \mathrm{Zn}$ [2] and $\mathrm{Mn}$ in chicken feed by high resolution continuum source flame atomic absorption spectrometry (HR-CS FAAS)[7-10] using new features.

\section{Experimental}

\section{Instrumentation}

An Analytik Jena ContrAA 700 High Resolution Continuum Source Atomic Absorption Spectrometer (Analytik Jena, Berlin,Germany) had been used for all measurements in this work. This spectrometer consists of a high-intensity xenon short-arc lamp, a high-resolution double echelle monochromator (DEMON) and a chargecoupled device (CCD) array detector[11]. All absorption lines in the range from $185 \mathrm{~nm}$ to $900 \mathrm{~nm}$ are provided by the high-intensity xenon short-arc lamp as the radiation source. The highest resolution of about $2 \mathrm{pm}$ is carried out by DEMON, including a pre-dispersing prism monochromator and a high-resolution echelle grating monochromator. 200 pixels of the linear CCD array detector are used for monitoring all spectral informations on both sides of center wavelength. The flame type was $\mathrm{C}_{2} \mathrm{H}_{2}$-air and the burner type was $100 \mathrm{~mm}$ in the process of determination. The fixed air flow was $470 \mathrm{~L} / \mathrm{h}$ for determination. The optimized determination conditions were shown in Table 1. 
Table 1 Determination conditions of HR-CS FAAS

\begin{tabular}{ccccc}
\hline Element & Wavelength $(\mathrm{nm})$ & Spectr.range & Fuel flow $(\mathrm{L} / \mathrm{h})$ & Burner height $(\mathrm{mm})$ \\
\hline $\mathrm{Ca}$ & 422.6728 & 200 & 70 & 6 \\
$\mathrm{Fe}$ & 248.3270 & 200 & 80 & 5 \\
$\mathrm{Zn}$ & 213.8570 & 200 & 90 & 6 \\
$\mathrm{Mn}$ & 279.4817 & 200 & 100 & 6 \\
\hline
\end{tabular}

Reagents and standards

The reagents were of guaranteed reagent. Ultrapure water with a resistivity of $18.2 \mathrm{M} \Omega \cdot \mathrm{cm}$ was obtained from a Milli-Q system (Millipore, Billerica, USA). Calibration solutions of Fe, $\mathrm{Zn}$ and $\mathrm{Mn}$ were prepared in the ultrapure water with $0.5 \%(\mathrm{v} / \mathrm{v}) \mathrm{HNO}_{3}$ and $0.1 \%(\mathrm{~m} / \mathrm{m}) \mathrm{KCl}$ by serial dilution of the stock solutions with $100 \mathrm{mg} / \mathrm{L}$ respectively, that of Ca were prepared in the ultrapure water with $0.5 \%(\mathrm{v} / \mathrm{v}) \mathrm{HNO}_{3}, 1 \%(\mathrm{~m} / \mathrm{m}) \mathrm{KCl}$ and $0.5 \%(\mathrm{~m} / \mathrm{m}) \mathrm{La}\left(\mathrm{NO}_{3}\right)_{3}$ by serial dilution of the stock solutions with $100 \mathrm{mg} / \mathrm{L}$ (National Chemical Reagent Company, Beijing, China). All glasswares were previously soaked overnight in dilute $\mathrm{HNO}_{3}(5 \% \mathrm{v} / \mathrm{v})$ for cleaning and were rinsed with abundant ultrapure water prior to avoid contamination.

Microwave digestion

The chicken feed were purchased from a feed store where farmers bought grain for their animals (Xuzhou, China) during 2015 and analyzed of their Ca, Fe, Zn and Mn contents. They were crushed to powder. Approximately a $0.5 \mathrm{~g}$ of the crushed sample was preprocessed with $5 \mathrm{~mL}$ of $\mathrm{HNO}_{3}$ and $2 \mathrm{~mL} \mathrm{H}_{2} \mathrm{O}_{2}$ in the PTFE jar, which was the process of heating to $120{ }^{\circ} \mathrm{C}$ for 60 min in an air-ventilated oven. The compound (sample and acids) was digested in the intelligent microwave digestion system (Xin-tuo, Shanghai,China) after adding again $2 \mathrm{~mL} \mathrm{H}_{2} \mathrm{O}_{2}$. A five stage program (Table 2) with a maximum pressure of 2.0 Mpa was chosen for achieving complete digestion of the crushed sample within the shorter time. The digestive liquor was diluted to $25 \mathrm{~mL}$ with the ultrapure water with $0.5 \%(\mathrm{v} / \mathrm{v}) \mathrm{HNO}_{3}$ and $0.1 \%(\mathrm{~m} / \mathrm{m}) \mathrm{KCl}$ when its volume was less than $3.0 \mathrm{~mL}$ for determination of Fe, $\mathrm{Zn}$ and $\mathrm{Mn}$. A $1.00 \mathrm{~mL}$ of that sample solution was diluted to $25 \mathrm{~mL}$ with the ultrapure water with $0.5 \%(\mathrm{v} / \mathrm{v}) \mathrm{HNO}_{3}, 1 \%(\mathrm{~m} / \mathrm{m}) \mathrm{KCl}$ and $0.5 \%(\mathrm{~m} / \mathrm{m}) \quad \mathrm{La}\left(\mathrm{NO}_{3}\right)_{3}$ for determination of $\mathrm{Ca}$. A blank digest was carried out in the same way. Three independent aboved treatments of the sample were performed for obtaining the average of repetitive determinations of $\mathrm{Ca}, \mathrm{Fe}, \mathrm{Zn}$ and $\mathrm{Mn}$.

Table 2 Microwave digestion program

\begin{tabular}{cccc}
\hline Stages & Pressure (Mpa) & Hold (min.) & Power $(\mathrm{W})$ \\
\hline 1 & 0.2 & 60 & 500 \\
2 & 0.5 & 60 & 1000 \\
3 & 1.0 & 120 & 1000 \\
4 & 1.5 & 120 & 1000 \\
5 & 2.0 & 60 & 1000 \\
\hline
\end{tabular}

\section{Results and discussion}

The analytical characteristic data of HR-CS FAAS were shown in Table 3. The calibration curves used to determine of $\mathrm{Ca}, \mathrm{Fe}, \mathrm{Zn}$ and $\mathrm{Mn}$ with HR-CS FAAS were built-up by measuring the absorbance of the calibration solutions in the selected determination conditions, as shown in Fig.1.. The correlation coefficients were $0.9992(\mathrm{Ca}), 0.9996(\mathrm{Fe}), 0.9989(\mathrm{Zn})$ and $0.9989(\mathrm{Mn})$, respectively. The characteristic concentrations were $0.092 \mathrm{mg} / \mathrm{L}(\mathrm{Ca}), 0.17 \mathrm{mg} / \mathrm{L}(\mathrm{Fe}), 0.033 \mathrm{mg} / \mathrm{L}$ $(\mathrm{Zn})$ and $0.15 \mathrm{mg} / \mathrm{L}(\mathrm{Mn})$, respectively. The relative standard deviations were $2.3 \%(\mathrm{Ca}), 1.9 \%(\mathrm{Fe})$, 2.6\% ( $\mathrm{Zn})$ and $2.1 \%(\mathrm{Mn})$, respectively. As can be seen, the proposed method represented one of more sensitive and more reproducibility methodologies for determination of the four metal elements.

The proposed means, using microwave digestion-HR-CS FAAS, had been applied to determination of the four metal elements in chicken feed and was verified through spike recovery tests[12]. The results, obtained as the average of three replicates of each element, were shown in Table 4. The contents in chicken feed were $6.75 \pm 0.12 \mathrm{mg} / \mathrm{g}(\mathrm{Ca}), 1.30 \pm 0.03 \mathrm{mg} / \mathrm{g}(\mathrm{Fe}), 0.174 \pm 0.05$ 
$\mathrm{mg} / \mathrm{g}(\mathrm{Zn})$ and $0.313 \pm 0.04 \mathrm{mg} / \mathrm{g}(\mathrm{Mn})$, respectively. The recoveries were $103.1 \pm 1.9 \%(\mathrm{Ca})$, 98.4 $\pm 2.3 \%(\mathrm{Fe}), 96.3 \pm 2.9 \%(\mathrm{Zn})$ and $97.7 \pm 1.8 \%(\mathrm{Mn})$, respectively. Therefore, the proposed method represented one of more accurate methodologies for the determination of the four metal elements.

Table 3 Analytical characteristic data of HR-CS FAAS

\begin{tabular}{|c|c|c|c|c|c|}
\hline Element & $\begin{array}{l}\text { Calibration function } \\
\qquad(C \text { in } \mathrm{mg} / \mathrm{L})\end{array}$ & $\begin{array}{c}\text { Correlation } \\
\text { coefficient } \\
\left(R^{2}\right)\end{array}$ & $\begin{array}{c}\text { Characteristic } \\
\text { concentration } \\
(\mathrm{mg} / \mathrm{L})\end{array}$ & $\begin{array}{l}\text { Concentration } \\
\text { range }(\mathrm{mg} / \mathrm{L})\end{array}$ & $\begin{array}{l}\text { Precision } \\
(\mathrm{RSD}, n=6)\end{array}$ \\
\hline $\mathrm{Ca}$ & $\begin{array}{c}\mathrm{A}=(0.0029893+0.0472545 \times \mathrm{c}) \\
/(1+0.0206515 \times \mathrm{c})\end{array}$ & 0.9992 & 0.092 & $0 \sim 10$ & $2.3 \%$ \\
\hline $\mathrm{Fe}$ & $\begin{array}{c}\mathrm{A}=(-0.0013854+0.0256013 \times \mathrm{c}) \\
/(1+0.0194315 \times \mathrm{c})\end{array}$ & 0.9996 & 0.17 & $0 \sim 5$ & $1.9 \%$ \\
\hline $\mathrm{Zn}$ & $\begin{array}{c}\mathrm{A}=(-0.0018482+0.1311885 \times \mathrm{c}) \\
/(1+0.1288429 \times \mathrm{c})\end{array}$ & 0.9989 & 0.033 & $0 \sim 4$ & $2.6 \%$ \\
\hline $\mathrm{Mn}$ & $\begin{array}{c}\mathrm{A}=(0.0003392+0.0285501 \times \mathrm{c}) \\
/(1+0.0148045 \times \mathrm{c})\end{array}$ & 0.9989 & 0.15 & $0 \sim 5$ & $2.1 \%$ \\
\hline
\end{tabular}
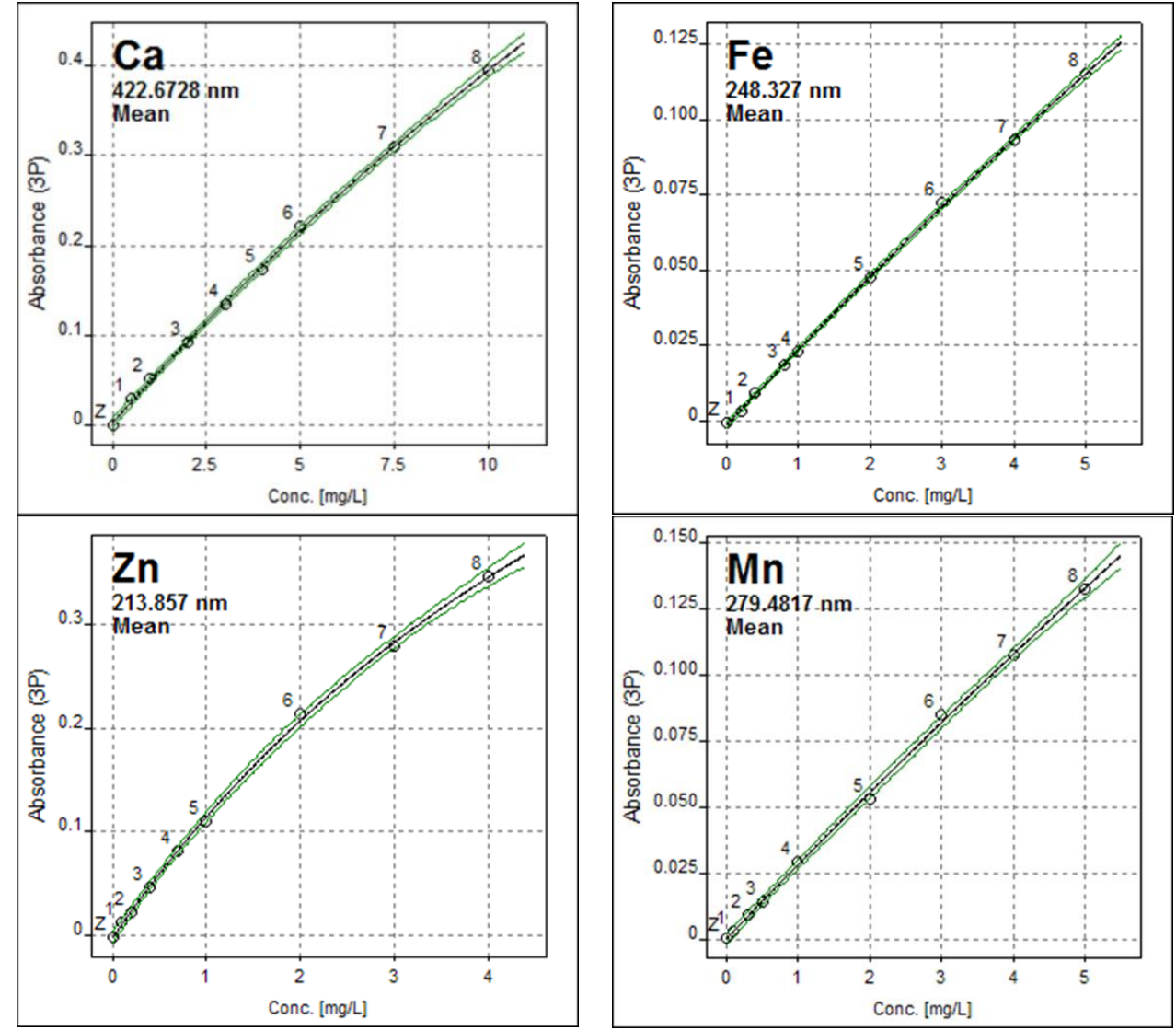

Fig.1. Calibration curve.

Table 4 Determination of $\mathrm{Ca}, \mathrm{Fe}, \mathrm{Zn}$ and $\mathrm{Mn}$ in chicken feed and recoveries (Avg...SD of three trials)

\begin{tabular}{cccc}
\hline Element & Content $(\mathrm{mg} / \mathrm{g})$ & Spiked $(\mathrm{mg} / \mathrm{g})$ & Recoveries $(\%)$ \\
\hline $\mathrm{Ca}$ & $6.75 \pm 0.12$ & 5.0 & $103.1 \pm 1.9$ \\
$\mathrm{Fe}$ & $1.30 \pm 0.03$ & 2.0 & $98.4 \pm 2.3$ \\
$\mathrm{Zn}$ & $0.174 \pm 0.05$ & 0.2 & $96.3 \pm 2.9$ \\
$\mathrm{Mn}$ & $0.313 \pm 0.04$ & 0.5 & $97.7 \pm 1.8$ \\
\hline
\end{tabular}




\section{Conclusions}

The developed means provided a exact and sensitive procedure for the determination of $\mathrm{Ca}, \mathrm{Fe}, \mathrm{Zn}$ and $\mathrm{Mn}$ in chicken feed by HR-CS FAAS after microwave digestion. Under the selected determination conditions, the correlation coefficients better than 0.998 , the relative standard deviations less than $2.6 \%$ and the recoveries between $96.3 \%$ and $103.1 \%$ were obtained for the four metal elements. The characteristic concentrations were $0.092 \mathrm{mg} / \mathrm{L}(\mathrm{Ca}), 0.17 \mathrm{mg} / \mathrm{L}(\mathrm{Fe}), 0.033$ $\mathrm{mg} / \mathrm{L}(\mathrm{Zn})$ and $0.15 \mathrm{mg} / \mathrm{L}(\mathrm{Mn})$, respectively. The results showed that the contents in chicken feed were $6.75 \pm 0.12 \mathrm{mg} / \mathrm{g}(\mathrm{Ca}), 1.30 \pm 0.03 \mathrm{mg} / \mathrm{g}(\mathrm{Fe}), 0.174 \pm 0.05 \mathrm{mg} / \mathrm{g}(\mathrm{Zn})$ and $0.313 \pm 0.04 \mathrm{mg} / \mathrm{g}(\mathrm{Mn})$, respectively. Low characteristic concentrations, good correlation coefficients and precisions, and high recoveries showed that the proposed method is accuracy, reliability and stability.

\section{Acknowledge ments}

This work was financially supported by the Open Project Program of Jiangsu Key Laboratory of Food Resource Development and Quality Safety, Xuzhou Institute of Technology (No. SPKF201317) and Spark Plan of China (No. 2013GA690417).

\section{References}

[1] Afridi H I, Kazi T G, Arain M B, et al. Determination of cadmium and lead in biological samples by three ultrasonic-based samples treatment procedures followed by electrothermal atomic absorption spectrometry[J]. Journal of AOAC International, 2007, 90(2): 470-478.

[2] Gao S Y. The Determination of Element Content in Burdock by Flame Atomic Absorption Spectrophotometry[J]. Journal of Xuzhou Institute of Technology, 2007, 6(22): 32-35.

[3] LIU L, YU M. Determination of calcium and magnesium in gelatin by noncomplete digestion-flame atomic absortion spectrometry [J]. Metallurgical Analysis, 2004, 5: 015.

[4] REN Ting, ZHAO Li-jiao, ZHONG Ru-gang. Determination of Aluminum in Wheat Flour Food by Microwave Digestion-High Resolution Continuous Source Graphite Furnace Atomic Absorption Spectrometry[J]. Spectroscopy and Spectral Analysis, 2011, 31(12): 3388-3391.

[5] Miao J Z. Technology of Bioaccumulation of Calcium by Submerged Fermentation of Gamoderma Lucidum and Its Analysis[J]. Journal of Xuzhou Institute of Technology, 2005, 5(20): 19-21.

[6] Miao J Z, Lv Z Q. The Study on the Bioenrichment of Iron in G.Lucidum by Deep-submerged Fermentation[J]. Journal of Xuzhou Institute of Technology, 2007, 6(22): 36-39.

[7] ALINE R B, EMILENE M B, CÉLINE L, et al. Method development for the determination of cadmium in fertilizer samples using high-resolution continuum source graphite furnace atomic absorption spectrometry and slurry sampling[J]. Spectrochimica Acta Part B, 2011, 66(7): 529-535.

[8] BAYSAL A, AKMAN S. A practical method for the determination of sulphur in coal samples by high-resolution continuum source flame atomic absorption spectrometry[ $\mathrm{J}]$. Talanta, 2011, 85(5): 2662-2665.

[9] OZBEK N, AKMAN S. Method development for the determination of fluorine in toothpaste via molecular absorption of aluminum mono fluoride using a high-resolution continuum source nitrous oxide/acetylene flame atomic absorption spectrophotometer[J]. Talanta, 2012, 94(30): 246-250.

[10] BRANDAO G C, de JESUS R M, da SILVA E G P, et al. Use of slurry sampling for the direct determination of zinc in yogurt by high resolution-continuum source flame atomic absorption spectrometry[J]. Talanta, 2010, 81(4): 1357-1359.

[11] Resano M, Briceño J, Belarra M A. Direct determination of $\mathrm{Hg}$ in polymers by solid sampling-graphite furnace atomic absorption spectrometry: a comparison of the performance of line source and continuum source instrumentation[J]. Spectrochimica Acta Part B: Atomic Spectroscopy, 2009, 64(6): 520-529. 
[12] Li Y, Chen S L, Wang S L, et al. Study on Determination Methods of Cadmium Content in Alcoholic Drink [J]. Journal of Xuzhou Institute of Technology(Natural Sciences Edition), 2012, 4(27): 16-19. 